\title{
Histopathological Findings of Endometrial Samples and its Correlation Between the Premenopausal and Postmenopausal Women in Abnormal Uterine Bleeding. Sharma $S,{ }^{1}$ Makaju $R,{ }^{1}$ Shrestha $S,{ }^{1}$ Shrestha $A^{2}$
}

\author{
${ }^{1}$ Department of Pathology \\ ${ }^{2}$ Department of Obstetrics and Gynecology \\ Kathmandu University School of Medical Sciences \\ Dhulikhel, Kavre, Nepal
}

\section{Corresponding Author}

Sujan Sharma

Department of Pathology

Kathmandu University School of Medical Sciences

Dhulikhel, Kavre, Nepal

Email: ssujans@hotmail.com

\section{Citation}

Sharma S, Makaju R, Shrestha S, Shrestha A. Histopathological Findings of Endometrial Samples and its Correlation Between the Premenopausal and Postmenopausal Women in Abnormal Uterine Bleeding. Kathmandu Univ Med J 2014;48(4):275-8.

\begin{abstract}
Background

Abnormal uterine bleeding is considered as one of the most common problems among women. The therapy is incomplete without knowing the underlying pathology.
\end{abstract}

\section{Objectives}

To determine the types and frequency of endometrial pathologies in patients presenting with abnormal uterine bleeding at Dhulikhel Hospital Kathmandu university Hospital.

\section{Methods}

This is retrospective study total 100 cases were included over a period of one year of Abnormal Uterine bleeding.

\section{Results}

Out of 100 cases of Abnormal uterine bleeding, $61 \%$ were due to non-organic cause with a commonest histopathological findings proliferative endometrium. $27 \%$ cases were due to organic cause with pregnancy related condition as most common finding. $12 \%$ were reported as inadequate. The rate of postmenopausal bleeding declined with increasing age in the postmenopausal period and endometritis was the predominant finding.

\section{Conclusion}

There is an age specific association of Abnormal uterine bleeding with increased incidence in perimenopausal age group. Postmenopausal bleeding declined with increasing with endometritis the most common finding. Dilation and curettage is helpful to exclude other organic pathology. It is useful for diagnosis and to know pathological incidence of organic lesions in cases of Abnormal uterine bleeding prior to surgery.

\section{KEY WORDS}

Abnormal uterine bleeding, histopathology 


\section{INTRODUCTION}

Abnormal uterine bleeding (AUB) may be defined as bleeding pattern that differs in frequency, duration and amount from a pattern observed during a normal menstrual cycle or after menopause. ${ }^{1}$ It is a common problem having a long list of causes in different age groups. ${ }^{2}$ The abnormal bleeding can be caused by a wide variety of disorders and may be the common presenting complaint in patients with malignant or pre-malignant endometrial lesion.,4

An endometrial biopsy is a safe and efficient officebased procedure for sampling the endometrium in a patient presenting with abnormal uterine bleeding. The endometrial sample provides a tissue diagnosis for wide range of morphologic patterns resulting from both normal and abnormal changes like hyperplasia, carcinoma, exogenous hormonal effects and infections and guiding further management. ${ }^{5,6}$

This study aimed to find out the histopathological pattern of the endometrium in abnormal uterine bleeding and to know the underlying causes for the abnormal uterine bleeding. Compare the histopathological findings between the premenopausal and postmenopausal women with abnormal uterine bleeding.

\section{METHODS}

The retrospective study was done at Dhulikhel Hospital Kathmandu University Hospital, Nepal. Total of 100 cases of abnormal uterine bleeding were included in the study. Cases were selected by reviewing the pathology reports of all cases who presented with complain of abnormal uterine bleeding. For each case, representative slides were reviewed along with clinical information including past history. The histopathological changes were identified and classified as mentioned below. ${ }^{7}$

The first category includes patients with abnormal uterine bleeding due to non-organic causes includes

\section{Secretory Endometrium}

2. Proliferative endometrium

3. Weakly proliferative endometrium

4. Decidual reaction

The second category includes patients with abnormal uterine bleeding due to organic causes

\section{Endometritis}

2. Endometrial carcinoma

3. Endometrial hyperplasia

4. Endometrial polyp

5. Pregnancy related condition

The third category includes patients whose specimens were insufficient for diagnosis.
The clinical differential diagnosis is different for various age groups and histopathological examination of materials obtained on endometrial curettage helps in diagnosis of these diseases presenting with AUB. ${ }^{8}$

Various causes of AUB were divided into four age groups. ${ }^{9,10}$

i) Adolescence

ii) Reproductive

iii) Perimenopausal

iv) Postmenopausal

Data was collected and analyzed for frequency,percentages and results were presented through figures.

\section{RESULTS}

Total 100 cases of AUB were enrolled in this study. Age ranges from 18 to 68 and most common age group of was later reproductive age (40-55 years).

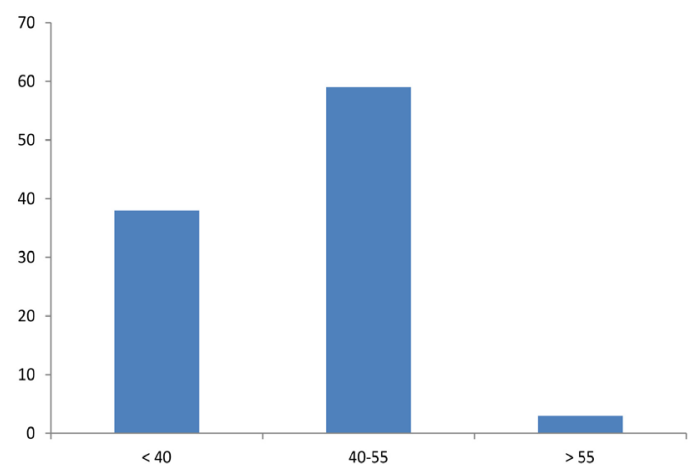

Figure 1. Age groups of patients with abnormal uterine bleeding

AUB was more commonly related to non-organic cause (61\%), of which the most cases were of perimenopausal patients(40-55 years). All cases of AUB in postmenopausal patients ( $>55$ years) were caused by organic lesions, (Table 1 ).

Table 1. Distribution of patients according to age group.

\begin{tabular}{|lccc|}
\hline Diagnostic group & \multicolumn{3}{c}{ Age } \\
& $<40$ & $40-55$ & $>55$ \\
\hline $\begin{array}{l}\text { AUB due to organic causes } \\
(\mathrm{n}=27)\end{array}$ & $16(59.2 \%)$ & $8(29.6 \%)$ & $3(11.1 \%)$ \\
\hline $\begin{array}{l}\text { AUB due to non organic } \\
\text { causes(n=61) }\end{array}$ & $20(32.7 \%)$ & $41(67.2 \%)$ & 0 \\
\hline $\begin{array}{l}\text { Inadequate for opinion }(\mathrm{n}=12) \\
\text { (12) }\end{array}$ & $2(16.6 \%)$ & $10(83.3 \%)$ & 0 \\
\hline
\end{tabular}

The most common histologic pattern was proliferative phase endometrium (47.5\%), Most patients clustered around pre-menopause and none beyond menopause (Table 2), followed by secretory endometrium.

Among the organic causes of AUB, pregnancy related condition was the most frequent cause (59.2\%), in those patients below the age of 40 years, followed by 
endometritis. Incidence of endometritis was frequently seen in perimenopause condition and showed most of the cases of chronic endometritis. (Table 3)

Table 2. Abnormal uterine bleeding due to non organic causes

\begin{tabular}{|c|c|c|c|}
\hline \multirow[t]{2}{*}{ Histopatholigical diagnosis } & \multicolumn{3}{|c|}{ Age } \\
\hline & $<40$ & $40-55$ & $>55$ \\
\hline Secretory endometrium ( $n=12)$ & $4(33.3 \%)$ & $8(66.6 \%)$ & 0 \\
\hline $\begin{array}{l}\text { Proliferative } \\
\text { endometrium(n=29 }\end{array}$ & $2(6.8 \%)$ & $27(93.1 \%)$ & 0 \\
\hline $\begin{array}{l}\text { Weakly proliferative } \\
\text { endometrium }(n=7)\end{array}$ & $1(14.2 \%)$ & $6(85.7 \%)$ & 0 \\
\hline Decidual reaction(n=13) & $13(100 \%)$ & 0 & 0 \\
\hline
\end{tabular}

Table 3. Abnormal uterine bleeding due to organic causes

\begin{tabular}{|lccc|}
\hline Histopathological diagnosis & \multicolumn{3}{c}{ Age } \\
\hline Endometrial polyp $(n=1)$ & $<40$ & $40-55$ & $>55$ \\
\hline Endometritis $(n=8)$ & $1(12.5 \%)$ & $5(62.5 \%)$ & $2(25 \%)$ \\
\hline Endometrial hyperplasia( $n=1)$ & 0 & 0 & $1(100 \%)$ \\
\hline Endometrial carcinoma $(n=1)$ & 0 & 0 & $1(100 \%)$ \\
\hline $\begin{array}{l}\text { Pregnancy related condition } \\
(n=16)\end{array}$ & $15(93.7 \%)$ & $1(6.2 \%)$ & 0 \\
\hline
\end{tabular}

Most common histopathological pattern in premenopausal bleeding was proliferative endometrium (34.9\%), followed by pregnancy related condition(19.2\%). Whereas for postmenopausal bleeding endometritis, the most common cause was increased with incidence of chronic endometritis. (Table 4)

Table 4. The histopathological findings in premenopausal and postmenopausal bleeding

\begin{tabular}{|lll|}
\hline Findings & $\begin{array}{l}\text { Premenopausal } \\
\text { bleeding }(\mathbf{n}=83)\end{array}$ & $\begin{array}{l}\text { Postmenopausal } \\
\text { bleeding }(\mathbf{n}=5)\end{array}$ \\
\hline $\begin{array}{l}\text { Secretory endometrium } \\
12(14.4 \%)\end{array}$ & 0 \\
\hline $\begin{array}{l}\text { Proliferative endometrium } \\
\text { Weakly proliferative endo- } \\
\text { metrium }\end{array}$ & $7(8.4 \%)$ & 0 \\
\hline Decidual reaction & $13(15.6 \%)$ & 0 \\
\hline Endometrial polyp & 0 & 0 \\
\hline Endometritis & $6(7.2 \%)$ & $1(20 \%)$ \\
\hline Endometrial hyperplasia & 0 & $2(40 \%)$ \\
\hline Endometrial carcinoma & 0 & $1(20 \%)$ \\
\hline Pregnancy related & $16(19.2 \%)$ & $1(20 \%)$ \\
\hline
\end{tabular}

\section{DISCUSSION}

AUB is a common problem in women due to wide range of morphologic patterns like carcinoma, hyperplasia, hormonal effects and infections. ${ }^{6}$ The clinical differential diagnosis is different for various age groups and histopathological examination of material obtained on endometrial curettage helps in diagnosis of these diseases presenting with AUB.

In our study the largest age group of patients wit AUB was found in 40-55 years, accounting for most of the cases. This is due to the fact that as menopause approaches, decreased number of ovarian follicles and their increased resistance to gonadotrophic stimulation, results in a low level of estrogen, which cannot keep the normal endometrium growing. ${ }^{11-13}$

In our study AUB was more commonly related to non organic cause and premenopausal women were most common age group. Study with similar findings were also reported. ${ }^{14}$ which is due to earlier evaluation, detection of wide range of morphologic pattern.

The most common histologic pattern in AUB was proliferative phase endometrium and most patients were clustered around premenopause. This is due to peak effect of hormonal imbalance as premenopausal age group patients are usually receiving hormone replacement therapy for different menopause related complaints these findings were similar to findings of Sarwar et al. ${ }^{15}$

In our study, insufficient for diagnosis rate was higher. These observation is due to inadequate sampling and after menopause the endometrium becomes atrophic due to lack of estrogen stimulation which may yield inadequate sample during endometrial biopsy. ${ }^{16}$

Chronic endometritis usually follows pregnancy, Intrauterine contraceptive device insertion and abortion. It may be due to viral, chlamydial, gonococcal, tuberculosis and nonspecific infection. The detection rate of chronic endometritis in our study was higher compared to other report. ${ }^{1}$ No specific infection like tuberculosis was noted in any case. This condition needs to be diagnosed because with specific treatment endometrium starts functioning normally. ${ }^{17}$

Endometrial hyperplasia is a common diagnosis often causing symptoms of irregular or prolonged bleeding. The incidence of hyperplasia in the present study was much lower than those observed by other authors. ${ }^{16,18}$

Pregnancy is the first consideration of AUB in the women of child bearing age. Similar findings have been reported in others literature. ${ }^{19}$

In our study only one case of endometrial carcinoma was found and the case was multiparous women. The lower incidence of carcinoma in our study may be due to inadequate sampling, not recognizing morphological pattern . So further more studies are required to identify cases of carcinoma. Higher incidence of carcinoma have been reported. ${ }^{20,21}$

In this study, the rate of postmenopausal bleeding declined with increasing. In our study,most of our patient was in early and late years of reproductive life and in most instances abnormal bleeding is due to the occurrence of anovulatory cycle that are most common at menarche and 
in perimenopausal bleeding. ${ }^{17}$ Anovulatory Dysfunctional uterine bleeding is due to disturbance of hypothalamicpituitary- ovarian axis that causes irregular, prolonged and at times heavy menstrual flow. ${ }^{22}$

\section{REFERENCES}

1. Zeeba S. Jairajpuri, S. Rana and S. Jetley. Atypical Uterine BleedingHistopathological audit of endometrium a study of 638 cases. Al Ameen J Med Sci 2013; 6 (1): 21-8.

2. Ely JW, Kennedy CM, Clark EC, Bowdler NC. Abnormal Uterine Bleeding: A Management Algorithm. J Am Board Fam Med 2006; 19 : 590-602.

3. Dangal G. A study of endometrium of patients with abnormal uterine bleeding at Chitwan valley. Kathmandu Univer Med J. 2003;1(2): 110-2.

4. Bhoomika D, Gauravi D. Histopathological study of endometrium in dysfunctional uterine bleeding. Int J Res Med. 2013: 2(1): 20-4.

5. Ran Svirsky, MD; Noam Smorgick, MD, MSc; Can we rely on blind endometrial biopsy for detection of focal intrauterine pathology? American Journal of Obstetrics \& Gynecology August 2008;115.e1.

6. Jignash P, Deepak D. Study of endometrial pathology in abnormal uterine bleeding. Int J Reprod Contracept Obstet Gynecol. 2013 Jun:2(2): 182-5.

7. Nadia A, Aiad A, Ehsan M. Abnormal uterine bleeding:A histopathological study. Diyala J of Med 2013;4(1):55-60.

8. Crum $C P$, Hornstein $M D$, Nucci $M R$, et al. Hertig and beyond.A systemic and practical approach to Endometrial biopsies. Adv Anat Pathol 2003; 10(6): 301-18.

9. Talat M, Saadia A, Aamir M. Histopathological pattern of abnormal uterine bleeding in endometrial biopsies. J of Basic and applied Sciences.2012;8:114-7.

10. Edward RG. Endometrial bleeding. Hum Reprod Update 2007;13(5):421-31.

11. Abdullah LS, Bondagji NS. Histopathological pattern of endometrial sampling performed for abnormal uterine bleeding. Bahrain Med Bull 2011;33(4):1-6

\section{CONCLUSION}

There is an age specific association of AUB with increase incidence in perimenopausal age group. Postmenopausal bleeding declined with increasing age and endometritis was the most common finding. Dilation and curettage is helpful to exclude other organic pathology, which mimics AUB. It is useful for diagnosis and to know pathological incidence of organic lesions in cases of AUB prior to surgery.

12. Davey DA. Dysfunctional Uterine Bleeding. In: whit field $C R$, ed Dewhurst's Textbook of Obs and Gynec for postgraduates.Glasgow. Blackwell science 1997.

13. Sharma JB. Dysfunctional Uterine Bleeding. Obstetrics and gynecology today 2000;5(11):20-5.

14. Ghani N.A, Abdulrazak A.A. Abnormal Uterine Bleeding: a Histopathological Study. World Res J of Clin Patho 2012; Volume 1, 6-08.

15. Sarwar A, ul Haque A. Types and frequencies of pathologies in Endometrial Curettings of Abnormal Uterine Bleeding. Int J Patho 2005; 3(2), 65-70.

16. Baral R, Pudasaini S. Histopathological pattern of Endometrial samples in Abnormal Uterine bleeding. J of Patho of Nepal 2011; Vol. 1, 13-16.

17. Saraswathi D, Thanka J, Shalinee R. Study of Endometrial Pathology in Abnormal Uterine Bleeding. Obstet and Gynec India 2011; 61:424 -30.

18. Muzzafar M, Akhatar KAK, Yasmin S. Menstrual irregularities with excessive blood loss: a clinico pathological correlation. J Pak Med Assoc 2005; 55: 486-9.

19. Ara S, Roohi M. abnormal Uterine Bleeding: Histopathological diagnosis by conventional dilatation and curettage. Prof Med J 2011; 18(4): 587-91.

20. Mahmoud M. M, Aseel G. R, Endometrial Histopathological changes in women with Abnormal Uterine bleeding in Kirkuk City, a Clinicopathological Study. Med J of Babylon 2013; Vol 10, 567-82.

21. Ejaz S, Zafar H, Waheed K. Causes of postmenopausal bleeding. A histopathological study. Cancer J Clin 2001;260-2.

22. Albers JR, Hull SK, Wesely RM. Abnormal Uterine bleeding. Am Fam Physician 2004;69(8):1951-6. 